\title{
Enfrentando os maus-tratos infantis nas Unidades de Saúde da Família: atuação dos enfermeiros
}

I ${ }^{1}$ Ramona Garcia Souza, ${ }^{2}$ Deisy Vital dos Santos |

Resumo: A violência é considerada um grave problema de saúde pública, apresentando-se de diferentes formas em contextos variados. Neste trabalho, destacam-se os maus-tratos a crianças, considerando a vulnerabilidade e as repercussões à saúde desses indivíduos. Buscou-se conhecer a atuação dos enfermeiros nas Unidades de Saúde da Família (USF) no enfrentamento da violência intrafamiliar contra crianças em um município do recôncavo baiano. Trata-se de pesquisa com abordagem qualitativa, cuja coleta de dados se deu através de entrevista semiestruturada. Utilizou-se o caminho da análise de conteúdo, modalidade da análise temática, que resultou em quatro grandes categorias: "Maus-tratos infantis: um problema de gerência?"; "Gerência e assistência (inter)agindo frente à violência”; "O feito e o 'por fazer' na assistência” e "As 'mil e nenhuma' dificuldades". A (in)visibilidade dos maus-tratos infantis influencia a atuação dos profissionais, tendo sido identificados inclusive o despreparo e as falhas no entendimento da violência e, consequentemente, no seu enfrentamento.

> Palavras-chave: enfermagem; violência na família; saúde da criança; Programa Saúde da Família.
1 Enfermeira, Universidade Federal do Recôncavo da Bahia (UFRB). Centro de Ciências da Saúde (CCS). Santo Antônio de Jesus, Bahia, Brasil. Endereço eletrônico: ramonagarcia1@ hotmail.com

${ }^{2}$ Mestre em Saúde Coletiva; professora assistente da Disciplina Atenção de Enfermagem à Saúde da Criança e do Adolescente. Centro de Ciências da Saúde (CCS), Universidade Federal do Recôncavo da Bahia (UFRB). Santo Antônio de Jesus, Bahia, Brasil. Endereço eletrônico: deisy@ufrb.edu.br

Recebido em: 07/03/2012 Aprovado em: 13/08/2013 


\section{Introdução}

A violência caracteriza-se como um fenômeno multideterminado, cuja conceituação vem sendo ampliada historicamente, já tendo sido considerada uma prática habitual, justificada e aceita pela sociedade. Desse modo, apresenta-se como um grave problema de saúde pública, visto que atinge parcela importante da população, provocando danos muitas vezes irreparáveis (BRASIL, 2001a; 2001b; PIRES; MIYAZAKI, 2005).

A vulnerabilidade das crianças nesse contexto é reconhecida na literatura, tendo em vista a extensão e a gravidade que os atos violentos e as repercussōes negativas assumem na saúde desses indivíduos em processo de crescimento e desenvolvimento. Assim, os atos violentos, quando não são fatais, geram danos à saúde das crianças como traumas, sequelas e incapacidades temporárias ou permanentes, provocando sofrimentos físicos e emocionais frequentemente associados (GRÜDTNER, 2005; SANCHEZ; MINAYO, 2006; SOUZA; JORGE, 2006).

No panorama brasileiro, segundo dados do Ministério da Saúde disponíveis no DATASUS (2010), no período de 2000 a 2008, 191.136 crianças e adolescentes morreram por acidentes e violências (causas externas). Isso representa, portanto, uma mudança no perfil de mortalidade no país, ao superar o número de 58.192 óbitos desse mesmo grupo etário por doenças infecciosas e parasitárias (SOUZA; JORGE, 2006). Por conseguinte, esses números nos chamam atenção para a necessidade de incentivar o desenvolvimento de pesquisas a fim de dimensionar esse problema no Nordeste, pois a maior parte dos trabalhos de base populacional e em serviços relacionados ao tema se concentra no Sudeste, especialmente nas áreas metropolitanas de São Paulo e do Rio de Janeiro (REICHENHEIM, et al., 2011).

Deve-se sublinhar que a violência intrafamiliar resulta das relações de poder estabelecidas entre os membros, repercutindo no seu estado de saúde, principalmente daqueles indivíduos mais indefesos, ou seja, sua definição considera as relaçôes em que se constrói e efetua a violência, e não somente o espaço em que ela ocorre (BRASIL, 2001a; SANCHEZ; MINAYO, 2006). Quanto aos tipos de maus-tratos infantis, estes podem se manifestar sob diferentes formas, que não ocorrem isoladamente e que fazem parte de uma sequência crescente de episódios com diferentes graus de severidade, a saber: negligência e abandono, abusos físicos, abuso sexual e abuso psicológico (BRASIL, 2002). 
Por tudo isso, nas últimas décadas, nota-se uma ampliação das políticas e estratégias de proteção à criança voltadas, principalmente, para essa questão. Nesse sentido, merecem destaque a Política Nacional de Redução da Morbimortalidade de Acidentes e Violências (BRASIL, 2001b), considerada o principal marco para a real inclusão da temática da violência na agenda do setor saúde, e o Estatuto da Criança e do Adolescente (ECA) (BRASIL, 1990), que torna obrigatória a comunicação das ocorrências de suspeita ou confirmação de maus-tratos ao Conselho Tutelar da respectiva localidade, destacando a responsabilidade dos profissionais de saúde (BEZERRA, 2006; MINAYO; DESLANDES, 2007; MARTINS; JORGE, 2010).

Portanto, o papel do setor saúde mostra-se indelegável na compreensão do problema, na atenção às crianças vitimizadas e no estabelecimento de compromissos e estratégias de prevenção à violência intrafamiliar, de maneira que as instituiçôes e serviços de saúde possam promover modelos de não violência, valorizando o papel ativo da comunidade na resolução de conflitos (BRASIL, 2001a; SOUZA; JORGE, 2006). Dito isso, a atuação em rede faz-se necessária a fim de configurar uma práxis integradora entre os profissionais e setores, capaz de fortalecer laços de proteção para a garantia dos direitos das crianças (DESLANDES, 2006).

Dentro desse contexto, "enfrentar" - no sentido de defrontar - apresenta um conceito mais adequado a essa problemática, em detrimento de "combater", cujo significado é extinguir. É utilizado, portanto, o termo "enfrentamento", por representar um conjunto de açôes articuladas que abrangem medidas para prevenção e diagnóstico das situações de violência, bem como para a garantia de atendimento integral e especializado para os casos confirmados (BRASIL, 2000). Logo, a Estratégia Saúde da Família (ESF), criada com o objetivo de reorientar o modelo assistencial, é apontada como lócus privilegiado dessas ações, sendo competência das equipes de Saúde da Família:

Conhecer, discutir e buscar a identificação dos fatores de risco na população adscrita, para facilitar a definição de açôes a serem desenvolvidas, com a finalidade de intervir preventivamente ou confirmar um diagnóstico, visando à adoção das medidas adequadas às diversas situaçôes de violência intrafamiliar (BRASIL, 2001a, p. 23).

No entanto, essas situações não são explícitas, pois o fato de o contexto familiar ser considerado um ambiente privado faz com que, tanto quanto possível, as 
famílias busquem esconder os conflitos e as violências, exigindo dos profissionais um olhar sensível e atento nas suas práticas com o intuito de revelar situações insuspeitas. Desse ponto de vista, o enfermeiro apresenta-se como agente necessário na articulação e no desenvolvimento de estratégias de enfrentamento à violência intrafamiliar contra crianças, uma vez que o seu trabalho está interligado ao gerenciamento do cuidado, sendo o profissional responsável por: coordenar e capacitar os Agentes Comunitários de Saúde (ACS) e a equipe de enfermagem (técnicos e auxiliares de enfermagem); executar açôes assistenciais nas Unidades de Saúde da Família (USF) de forma integral; e planejar e gerenciar os serviços oferecidos (BRASIL, 1986; 2006).

Desse modo, destacamos a importância de discutir a atuação dos enfermeiros nesse contexto, reafirmando sua responsabilidade profissional e buscando suscitar um movimento individual, por meio da reflexão sobre o assunto. Assim, esperamos contribuir para a visibilidade dessa problemática, enfatizando as ações de enfrentamento à violência intrafamiliar contra crianças, de modo que o setor saúde faça efetivamente parte da necessária rede de proteção infantil. Com base no exposto, este estudo teve como objetivo conhecer a atuação dos enfermeiros nas USF quanto ao enfrentamento da violência intrafamiliar contra crianças em um município do recôncavo da Bahia.

\section{Métodos}

Trata-se de uma pesquisa do tipo exploratória, descritiva, com abordagem qualitativa, realizada com enfermeiros das USF situadas na zona urbana de um município do recôncavo da Bahia, com 90.985 habitantes (IBGE, 2010). Dados do Centro de Referência Especializado de Assistência Social (CREAS) do município apontam um aumento de 51\% (75 casos) nos atendimentos dos casos de maus-tratos infanto-juvenis, quando comparados os registros de 2009 (147 casos) aos dados preliminares do período de janeiro a agosto de 2010 (222 casos), reafirmando a importância da escolha desse cenário para estudo. ${ }^{1}$

Nesse município, existem vinte e uma USF localizadas na zona urbana. Dessas, doze responderam ao critério de inclusão que foi ter enfermeiros com tempo de atuação mínimo na unidade de seis meses. Assim, foi necessário realizar sorteio da ordem de convite dos sujeitos, evitando, dessa forma, a indução na sua escolha. A coleta de dados ocorreu no período de março a abril de 2011, e a captação de 
novos sujeitos foi interrompida por saturação teórica. Desse modo, a amostra

foi constituída por oito enfermeiros. Utilizamos entrevistas semiestruturadas, realizadas mediante a assinatura de Termo de Consentimento Livre e Esclarecido (TCLE), as quais, posteriormente, foram transcritas e sistematizadas para análise.

Os dados foram avaliados seguindo o caminho da análise de conteúdo, modalidade da análise temática (MINAYO, 2006), e divididos nas seguintes etapas: pré-análise, exploração do material, tratamento dos resultados e interpretação.

Esta pesquisa foi aprovada pelo Comitê de Ética da Faculdade Maria Milza (FAMAM), protocolo no 013/2011. A fim de garantir o anonimato das USF e dos participantes, identificamo-los por letras e números na apresentação dos resultados.

\section{Resultados e discussão}

Serão apresentadas e discutidas inicialmente as características dos sujeitos participantes do estudo, a fim de melhor compreender a influência desses aspectos na sua atuação. Posteriormente, será realizada análise do conteúdo das entrevistas.

\section{Caracterização dos sujeitos}

Participaram desta pesquisa sete enfermeiras e um enfermeiro, com média etária de 31 anos e tempo de formação inferior a cinco anos, em sua maioria. A observação de que os sujeitos entrevistados são, em geral, mulheres, jovens e com pouco tempo de formação, suscita a discussão a respeito da influência desses aspectos na sua atuação frente a violência intrafamiliar contra crianças. Percebida de diferentes formas por homens e mulheres por ter sido, historicamente, aceita pela sociedade como meio empregado de educar, a violência vem ganhando maior atenção somente em épocas pós-modernas, o que pode ter favorecido a inclusão desse tema na formação acadêmica dos entrevistados (PIRES; MIYAZAKI, 2005; GRÜDTNER, 2005; FAÚNDES et al., 2006; RODRIGUES et al., 2008; MARTINS; JORGE, 2010).

A média do tempo de trabalho na unidade foi de um ano e seis meses. Isso sinaliza uma possível rotatividade desses profissionais, principalmente quando comparamos o tempo de serviço com o tempo médio de implantação das unidades, sete anos e nove meses. Tal aspecto pode afetar o envolvimento do 
profissional com a comunidade e a familiarização com a equipe, comprometendo a criação de vínculo e o relacionamento de confiança com as famílias, o que poderia facilitar a revelação da violência e abrir espaços de intervenção e ajuda (BRASIL, 2001a; KRUG et al., 2010).

\section{Maus-tratos infantis: um problema de gerência?}

Observamos nas narrativas dos enfermeiros que sua abordagem do tema e sua atitude quanto à atuação na gerência estão intimamente relacionadas à visibilidade ou não do problema no seu cotidiano, corroborando com outros estudos (GOMES et al., 2002). Por conseguinte, destacam-se nas falas dos profissionais diferentes percepções e atitudes frente aos maus-tratos infantis, que variam desde o reconhecimento da existência do problema na comunidade até sua negação. Diante de tal panorama, observamos na fala a seguir que a violência contra crianças tem sido vista como um problema de menor importância quando comparado a patologias e agravos de maior visibilidade.

[...] a gente tá muito ligado às patologias e esquece desses tipos de caso, mas acontece sim [...]. (E3)

Assim, ao se revelar uma realidade pouco ou mal conhecida, essa situação acaba por configurar-se como mais uma forma de violência por parte dos profissionais (ARPINI et al., 2008). Por outro lado, a invisibilidade do problema pode levar à negação de sua existência na comunidade, tornando-se um empecilho para a atuação esperada desses sujeitos diante da questão.

[...] eu nunca peguei um caso de violência contra criança [...]. A gente procura tá se envolvendo com os problemas da comunidade, e como esse não é um problema, pelo menos, nunca foi $[\ldots]$. (E5)

Dentre outros aspectos, as dificuldades de poder ver dos profissionais de saúde incluem: o despreparo profissional na identificação dos casos, a falta de suporte institucional, o não reconhecimento da violência como problema de saúde e os sentimentos de impotência e banalização da violência (VECINA; MACHADO, 2010). A esse respeito, reiteramos a responsabilidade ética e social do enfermeiro, que deve contrapor os fatores limitantes de sua atuação a fim de assumir o seu papel na garantia dos direitos infantis previstos no ECA.

As entrevistas revelaram, inclusive, a educação permanente como instrumento para o enfrentamento da violência intrafamiliar contra crianças, embora 
possamos observar diferentes percepções no que tange à necessidade de capacitar os Agentes Comunitários de Saúde (ACS) e a equipe de enfermagem voltada para essas questões. No trecho em destaque, por exemplo, o sujeito afirma orientar a equipe da USF no que concerne à identificação dos casos de violência.

[...] pra nas visitas domiciliares, eles [ACS] ficarem atentos, a questão da violência.

[...] Pra quando chegar uma criança na sala de vacina, na sala de curativo, todos da unidade ter [sic] a mesma, assim, linha, né, de linguagem e de olhar para aquele tipo de violência intrafamiliar. (E8)

Dentre as atribuições do enfermeiro está a de educador, sendo, portanto, de extrema importância que este capacite sua equipe. $\mathrm{O}$ não reconhecimento desse papel pode ser um fator impeditivo para o enfrentamento do problema no contexto de trabalho em que estão inseridos (WOISKI; ROCHA, 2010; ANDRADE et al., 2011). Entretanto, nos registros apresentados a seguir, encontramos relatos de que essas ações não são desenvolvidas junto aos ACS:

[...] Eu acho que não seria difícil para os agentes estarem identificando isso, apesar de não ter tido capacitação (E5).

Deve-se sublinhar que existem evidências na literatura de que os ACS podem não identificar situaçôes de violência, haja vista a influência exercida pelas experiências da própria infância e o aprendizado individual na forma de lidar com essa questão no dia a dia do serviço (ASSIS, 2006; RAMOS; SILVA, 2011). Nesse sentido, a capacitação é um instrumento gerencial que viabiliza mudanças na cultura organizacional, contribuindo com a motivação do ACS e influenciando-a positivamente. Afinal de contas, trabalhadores qualificados têm maiores condições de esclarecimento, trazendo benefícios para a comunidade, principalmente quando se considera a posição estratégica ocupada pelos ACS no contexto das práticas em Saúde da Família (PÁDUA; VANONE; NASCIMENTO, 2009).

\section{Gerência e assistência (inter)agindo frente à violência}

As falas dos entrevistados retratam as atividades de educação em saúde e as ações intersetoriais e interdisciplinares enquanto práticas comuns à gerência e assistência para o enfrentamento da violência intrafamiliar contra crianças. Sendo assim, sobre a educação em saúde, destacamos um trecho em que o sujeito reconhece essas atividades como ferramentas necessárias para fornecer informação à comunidade. 
No que diz respeito à prevenção e a promoção em saúde, deve-se atentar para a Educação em Saúde como um alicerce da ESF, uma das funções essenciais dos enfermeiros, devendo ser valorizada pela possibilidade de modificar o modo de vida e saúde da comunidade. $\mathrm{O}$ depoimento do sujeito apresentado a seguir sugere que essas atividades são realizadas, porém demonstra que o tema da violência é abordado com a comunidade de forma pontual, em detrimento de outras demandas da USF.

[...] infelizmente também em decorrência de outras demandas, às vezes, fica a desejar a questão das atividades educativas, né, com um enfoque maior (E6).

A atenção integral a crianças deve ser um compromisso dos profissionais inseridos na ESF, principalmente em se tratando daquelas em situação de violência. Portanto, a fim de reduzir os efeitos deletérios, a aplicação de medidas de promoção, prevenção e proteção, na perspectiva da educação em saúde, deve ser prioridade absoluta, como define o ECA (BRASIL, 1990). Ao contrário das falas anteriores, relacionamos um trecho em que o sujeito demonstra a incompreensão da violência contra crianças enquanto algo a ser enfrentado no âmbito local.

[...] como nunca apareceu um caso desse pra mim, eu ainda não percebi a necessidade de tá tratando isso com a comunidade (E5).

Deve-se salientar que os maus-tratos infantis são considerados, atualmente, grave problema de saúde pública. Logo, ressalta-se a importância de o enfermeiro atuar em estratégias dirigidas ao conjunto da população no esforço de reduzir a incidência e a prevalência dos casos de violência (ALGERI; SOUZA, 2006).

Em suma, apenas três participantes fizeram referência à educação em saúde, sendo um deles de caráter divergente, alertando para a necessidade de dar visibilidade a esse problema. Além disso, a realização dessas atividades com a comunidade é importante ferramenta para a mobilização da coletividade, no que tange ao enfrentamento da violência, à construção da cidadania e à promoção da cultura de paz e da qualidade de vida da população.

Já diante de um caso identificado, os sujeitos referiram a intersetorialidade como ação gerencial/assistencial necessária:

[...] parcerias como CRAS, como o conselho tutelar, o PETI, as creches, até pra tá vendo também outros artifícios [...] (E7). 
De fato, a complexidade desse problema de saúde, exige uma abordagem ampla, envolvendo diferentes setores e profissionais. Dessa forma, faz-se necessária a orientação dos profissionais para que sejam tomadas medidas adequadas de encaminhamento dos casos suspeitos e confirmados, principalmente no que concerne a sua notificação (MARTINS; JORGE, 2009). Pôde-se evidenciar, ainda, a concepção equivocada de que a violência resume-se a uma questão social; ou seja, ao acionar diferentes setores, o profissional de saúde pretende transferir aos demais órgãos a responsabilidade que lhe cabe.

[...] eu acionaria a ação social, porque eu acho que isso é questão social, e acionaria também o conselho tutelar. Porque existem órgãos responsáveis pra isso (E5).

No entanto, o acompanhamento do trabalho do Conselho Tutelar por parte dos profissionais de saúde é imprescindível para a construção de uma parceria que permita compartilhar responsabilidades sobre a decisão a ser tomada para o melhor encaminhamento dos casos atendidos (BRASIL, 2002). Além disso, não podemos perder de vista que essas crianças e famílias em situação de violência estão inseridas no território coberto por uma equipe de Saúde da Família, sendo, portanto, de sua responsabilidade assisti-las integralmente. Também têm contribuído para o enfrentamento do problema as açôes intrasetoriais, de cunho interdisciplinar, como mostra o trecho a seguir:

[...] a gente tem a psicóloga do NASF, né? [...] quando a gente vê alguns casos desses, a gente procura trabalhar em conjunto né? [...] (E3)

Fica evidente a importância dos profissionais do Núcleo de Apoio à Saúde da Família (NASF) na prestação de apoio técnico, destacando-se o papel do psicólogo. Nesse contexto, é essencial que se estabeleça um fluxo de acolhimento, notificação, investigação epidemiológica, atendimento e acompanhamento integral das crianças vitimizadas e suas famílias (BRASIL, 2010), definindo as responsabilidades de cada setor, para que os enfermeiros inseridos na ESF possam compreender seus limites e possibilidades de atuação.

\section{O feito e o "por fazer" na assistência}

As falas dos sujeitos evidenciam a compreensão de que o enfrentamento da violência intrafamiliar contra crianças se dá a partir da confirmação dos casos. Assim sendo, as ações assistenciais mostram-se voltadas para a identificação dos maus-tratos, principalmente durante as consultas de Acompanhamento do 
Crescimento e Desenvolvimento (ACD) infantil, ou seja, no consultório da USF, demostrando a centralização do serviço nesse espaço. Notamos que a presença do agravo é confirmada através da observação de sinais físicos e do comportamento apresentado pela criança, como pode ser observado nos recortes:

Geralmente quando a gente atenta né, é quando chega uma criança com alguma mancha ou alguma coisa [...]. (E2)

[...] quando a mãe ou pai traz a criança pra poder, né, passar pela consulta de ACD. Então, existe também a questão de tá inspecionando, de tá observando essa criança [...]. (E6)

Ao refletirmos sobre os diferentes tipos de maus-tratos, vislumbramos que a identificação ou a suspeita de violência depende da possibilidade do profissional ser capaz de reconhecer situações de risco nas famílias, bem como sinais e sintomas sugestivos de violência (GOMES et al., 2002). Desse modo, os serviços que atendem crianças devem incorporar à sua rotina a vigilância aos maus-tratos infantis (BRASIL, 2002). No entanto, o conteúdo da narrativa a seguir mostrase divergente a essa recomendação:

[...] Se a gente vê alguma coisa mais suspeita em relação à violência, a gente questiona.

[...] Mas não é uma pergunta frequente que eu faço. Não é de rotina. Deveria ser, mas não é. A gente se passa, mas se eu vejo alguma coisa suspeita eu tento indagar pra ver se solta alguma coisa, mas até o momento, não (E4).

Importante observar que os profissionais de saúde podem ser os primeiros a detectar os casos e denunciar os maus-tratos por conta de sua prática e conhecimentos que permeiam sua área de atuação (RAMOS; SILVA, 2011). Nesse sentido, espera-se que o enfermeiro também possa atuar na prevenção desse agravo durante as consultas de ACD, através de orientaçooes voltadas à família, como podemos evidenciar nos registros:

[...] orienta a mãe [...]. Sempre fala pra não deixar ninguém pegar a criança, né, de tá acalentando, só esses cuidados assim, né, de violência sexual [...] (E7).

[...] Sempre a gente orienta nas questôes dos bons-tratos [...] (E8).

A atuação mais eficaz é aquela que se torna presente na vida cotidiana das famílias e das comunidades, aproximando-se da realidade em que estão inseridas. Logo, destaca-se também a importância de promover ações para a sensibilização da população em geral sobre o funcionamento do "DisqueDenúncia”, mobilizando, assim, a comunidade para a vigilância desse agravo (COSTA et al., 2007; BRASIL, 2010). A visita domiciliar é apontada, ainda, 
como um instrumento fundamental para o reconhecimento de tais situações na área de abrangência da USF.

[...] naquela casa tem uma criança, então a gente não deixa né, de dar uma olhada e ver como é que tá [...] (E1).

Nesse sentido, a visita domiciliar configura-se como mais uma possibilidade de intervenção, na medida em que permite ao profissional aproximar-se do ambiente privado das famílias e conhecer a dinâmica interacional das relações construídas entre seus membros (ASSIS; DESLANDES, 2006). Em suma, percebemos que os entrevistados "tem feito", mas, a partir da compreensão de que o enfrentamento se dá através da confirmação de casos, portanto, faz-se necessária a ampliação desse conceito para a compreensão do "por fazer" na sua práxis dentro desse contexto.

\section{As "mil e nenhuma" dificuldades}

Muitos são os entraves encontrados no cotidiano das USF que se configuram como desafios a serem discutidos por usuários, gestores e profissionais, a fim de se buscarem estratégias políticas e sociais integradas, capazes de construir uma rede de atendimento efetiva (LIMA et al., 2009). Dessarte, algumas narrativas referiram não haver "nenhuma” dificuldade:

No momento eu não tô vendo nenhuma dificuldade [...] (E7).

Eu não tenho tido dificuldade [...] (E8).

Entretanto, tais dificuldades também podem se fazer invisíveis aos profissionais, levando-nos a questionar se os sujeitos de fato não as encontram no serviço ou não as percebem. Isso demonstra a necessidade de maior reflexão sobre essas práticas no intuito de melhor compreendê-las, pois a ausência de dificuldades no enfrentamento da violência parece ser algo excepcional. Portanto, apresentamos as "mil" dificuldades apontadas pelos entrevistados, corroborando com outros trabalhos (LIMA et al., 2009).

$\mathrm{Na}$ perspectiva de diminuir esses entraves, entende-se que os enfermeiros devem conhecer essas questôes desde a sua formação. No entanto, a não problematização do tema durante a graduação foi apontada como dificuldade para a atuação dos sujeitos (SILVA et al., 2009).

Existe um entravezinho, né, que é justamente a questão da formação acadêmica, porque no período em que eu passei pela Academia, não foi abordado tal tema [...] (E6). 
Entretanto, deve-se esclarecer que a Universidade, enquanto órgão educador e local de produção de conhecimento, tem a responsabilidade na formação de profissionais de saúde capazes de lidar com a violência em suas múltiplas faces (ALGERI; SOUZA, 2006). Dentre os resultados obtidos, foram características marcantes das narrativas, ainda, a falta de segurança nas unidades de saúde, o medo de se envolver com indivíduos com o perfil violento e o temor de represálias.

[...] A questão de, por exemplo, algumas pessoas se exporem, né? [...] A gente não sabe se a gente vai ter segurança em relação a isso, por a gente tá todos os dias aqui no bairro. [...]. (E6)

Assim, verifica-se que os efeitos da violência, evidenciados pelo medo de vingança e insegurança, podem interferir no funcionamento do serviço de saúde, na medida em que contribuem para a atuação paralisante dos profissionais (ANDRADE et al., 2011). Essa dificuldade é ampliada quando se acrescenta a percepção de gênero: a enfermagem é uma profissão eminentemente exercida por mulheres (GRÜDTNER, 2005). O trecho abaixo confirma tais colocações:

[...] A maioria das equipes são compostas [sic] por mulheres, então, assim, realmente, pra gente é muito complicado realmente fazer uma denúncia né, de um pai que já tem um perfil violento e ai, ir lá e fazer uma denúncia, depois a gente fica com medo né [...] (E1).

Em outras palavras, a falta de resguardo nas unidades aliada à dominação masculina apresenta-se como provável fonte do medo e apreensão em relação aos agressores familiares, motivando o silêncio e contribuindo para a manutenção da situação de violência (GRÜDTNER, 2005; OLIVEIRA; FONSECA, 2007; ANDRADE et al., 2011). Há, também, a dificuldade em lidar com o tema aqui tratado, visto que se configura como uma questão desafiadora no cotidiano dos trabalhadores.

[...] é difícil, o tema, pra você trabalhar e chegar, tá conduzindo, é difícil [...] (E4).

Reconhecendo essa dificuldade, o Ministério da Saúde (BRASIL, 2010) buscou orientar as práticas dos profissionais para a procura de recursos da própria comunidade, dos projetos sociais, de pessoas de fora e também de dentro das famílias que possam contribuir para o enfrentamento dessa problemática, devendo ainda considerar as prioridades e as possibilidades de cada território. Por sua vez, a concretização de parcerias com outros setores aparece nas falas como entrave:

[...] E às vezes eu percebo que existe uma dificuldade de tá estreitando parcerias com outras instituições também (E6). 
Dessa forma, a falta de diálogo com as intituições de proteção à criança restringem a abordagem, o encaminhamento e a assistência oferecida às vítimas, além da articulação de medidas preventivas junto à comunidade e às famílias (ANDRADE et al., 2011). Outra dificuldade apontada pelos entrevistados diz respeito à falta de tempo:

[...] É a parte mais de orientação, de tudo, que às vezes foge muito porque a gente não tem tempo [...] (E8).

No contato com as famílias, porém, por menor que seja o tempo disponível para o atendimento, os enfermeiros precisam orientar as famílias quanto ao seu papel na proteção das crianças, enfatizando valores familiares e sociais importantes para uma convivência saudável e motivando a expressão de afeto e carinho (BRASIL, 2010). Em outros discursos, percebemos a responsabilização da família pelo silêncio e pela dificuldade de "poder ver" desses profissionais:

Sim, a questão dos próprios pais. Os pais não trazem as crianças na unidade quando sofre algum tipo de violência, principalmente a física [...] (E3).

Nessa perspectiva, não se deve negligenciar a responsabilidade dos familiares diante das situações de maus-tratos infantis. No entanto, o enfoque no enfrentamento da violência não deve ser o de buscar culpados e, sim, alternativas para a prevenção, até mesmo porque não cabe apenas à família o papel de denunciar essas situações (RAMOS; SILVA, 2011). É importante enfatizar que o tipo de violência a que nos referimos compreende o agressor enquanto membro do núcleo familiar, e este muitas vezes beneficia-se do medo e de ameaças para perpetrar os atos violentos e manter o silêncio.

\section{Consideraçôes finais}

Por certo que a visibilidade ou invisibilidade dos maus-tratos infantis na área de abrangência da unidade tenha sido um dos aspectos que se mostrou com maior poder de influenciar a atuação dos enfermeiros. Ademais, compreendemos que a atuação voltada para o enfrentamento da violência intrafamiliar contra crianças perpassa a gerência (educação permanente) e a assistência (consultas de ACD, visita domiciliar), bem como a interação entre elas (educação em saúde, ações intersetoriais e interdisciplinares), entendendo que estas integram o elenco de atribuições desse profissional. 
Destacam-se, ainda, as lacunas evidentes na compreensão do direcionamento dos casos identificados e a falta de diálogo entre a USF e os órgãos de proteção ao menor, de onde extraímos que a intersetorialidade citada nas falas se refere apenas ao encaminhamento das vítimas, não havendo a preocupação com o acompanhamento dos casos, quiçá referência aos planos de cuidados a esses indivíduos, à família e aos agressores. Outro ponto a salientar compreende o fato de a notificação não ter aparecido nas narrativas, o que mostra uma possível falha no fluxo de informações dentro da rede intersetorial e uma desvalorização desse instrumento.

Outrossim, a capacitação dos enfermeiros torna-se imprescindível, o que nos remete às dificuldades apontadas pelos sujeitos, reafimando a importância de incluir no processo de ensino-aprendizagem da enfermagem a abordagem desse tema e o incentivo à participação da universidade na educação permanente dos profissionais nos diferentes campos de estágio. Também faz-se necessária a estruturação de uma rede efetiva de acolhimento e enfrentamento da violência, assim como a construção de protocolos que definam papéis/responsabilidades, com o propósito de garantir a resolutividade dos casos identificados e ampliar as medidas de proteção às crianças.

Além disso, as falas demonstraram a necessidade de transcendermos a dimensão biológica do cuidar. Por isso, vemos a possibilidade de incluir na ficha de atendimento das consultas de ACD, questóes referentes aos sinais sugestivos de violência, servindo de alerta para essa questão. Com base no exposto, reiteramos o impacto positivo que esperamos provocar com este estudo ao dar visibilidade à problemática da violência intrafamiliar contra crianças e às possibilidades de atuação do enfermeiro na USF, abrindo espaços de discussão sobre as suas práticas, buscando qualificá-las ${ }^{2}$.

\section{Referências}

ALGERI, S.; SOUZA, L.M. Violência contra crianças e adolescentes: um desafio no cotidiano da equipe de enfermagem. Rev Latino-am Enfermagem, v.14, n.4, p.625-631, jul-ago 2006.

ANDRADE, E.M. et al. A visão dos profissionais de saúde em relação à violência doméstica contra crianças e adolescentes: um estudo qualitativo. Saúde Soc., v.20, n.1, p.147-155, janmar 2011.

ARPINI, D.M. et al. A revelação e a notificação das situações de violência contra a infância e a adolescência. Psicologia em Revista. Belo Horizonte, v.14, n.2, p.95-112, dez. 2008. 
ASSIS, S.G. de. Aspectos conceituais da violência na infância e adolescência. In: LIMA, C.A. (Coord.) et al. Violência faz mal à saúde. Brasília: Ministério da Saúde, 2006. p.39-45. ASSIS, S.G. de; DESLANDES, S.F. Abuso físico em diferentes contextos de socialização infanto-juvenil. In: LIMA, C. A. (Coord.) et al. Violência faz mal à saúde. Brasília: Ministério da Saúde, 2006. p.47-57.

BEZERRA, S.de C. Estatuto da Criança e do Adolescente: marco da proteção integral. In: LIMA, C.A. (Coord.) et al. Violência faz mal à saúde. Brasília: Ministério da Saúde, 2006. p. 17-22.

BRASIL. Lei no 7.498 de 25 de junho de 1986. Dispóe sobre a regulamentação do exercício da Enfermagem e dá outras providências. Diário Oficial [da] República Federativa do Brasil, seção 1, Brasília, 1986.

BRASIL. Lei Federal no 8069 de 1990. Dispõe sobre o Estatuto da Criança e do Adolescente e dá outras providências. Diário Oficial [da] República Federativa do Brasil, 13 de julho de 1990, seção 1. Disponível em: <http://www.planalto.gov.br/ccivil_03/Leis/L8069.htm>. Acesso em: 30 out. 2010.

BRASIL. Secretaria de Estado dos Direitos Humanos, Departamento da Criança e do Adolescente. Plano Nacional de Enfrentamento da Violência Sexual Infanto-Juvenil. 1ed. Brasília: SEDH/DCA, 2000. 54 p. (Série Subsídios, 5).

BRASIL. Ministério da Saúde. Secretaria de Políticas de Saúde. Violência intrafamiliar: orientaçôes para prática em serviço. Brasília: Ministério da Saúde, 2001a. 96 p.: il. (Série Cadernos de Atenção Básica; n. 8) - (Série A. Normas e Manuais Técnicos; n. 131).

BRASIL. Ministério da Saúde. Política Nacional de redução da morbimortalidade por acidentes e violências: Portaria MS/GM no 737, de 16 de maio de 2001. Diário Oficial [da] República Federativa do Brasil, n.96, seção 1E de 18 de maio de 2001. Brasília: Ministério da Saúde, 2001b (Série E. Legislação de Saúde, n. 8).

BRASIL. Ministério da Saúde. Secretaria de Assistência à Saúde. Notificação de maustratos contra crianças e adolescentes: um passo a mais na cidadania em saúde. 2 ed. Brasília: Ministério da Saúde, 2002.

BRASIL. Ministério da Saúde. Secretaria de Atenção à Saúde. Departamento de Atenção Básica. Política Nacional de Atenção Básica. Brasília: Ministério da Saúde, 2006. 60 p. (Série A. Normas e Manuais Técnicos) (Série Pactos pela Saúde 2006, v.4).

BRASIL. Ministério da Saúde. Secretaria de Atenção à Saúde. Departamento de Ações Programáticas Estratégicas. Linha de cuidado para a atenção integral à saúde de crianças, adolescentes e suas famílias em situação de violências: orientação para gestores e profissionais de saúde. Brasília: Ministério da Saúde, 2010.104 p.: il. (Série F. Comunicação e Educação em Saúde). 
COSTA, M.C.O. et al. O perfil da violência contra crianças e adolescentes, segundo registros dos Conselhos Tutelares: vítimas, agressores e manifestações de violência. Ciência \& Saúde Coletiva, v.12, n.5, p.1129-1141, 2007.

DATASUS [página na internet]. Brasil. Ministério da Saúde. Departamento de informática do SUS - Datasus. Tecnologia da informação a serviço do SUS. Óbitos por causas externas. Brasília: DATASUS; 2010. Disponível em: <www.datasus.gov.br>. Acesso em: 22 dez 2010. DESLANDES, S.F. Redes de proteção social e redes sociais: uma práxis integradora. In: LIMA, C.A. (Coord.) et al. Violência faz mal à saúde. Brasília: Ministério da Saúde, 2006. p. 135-141. FAÚNDES, A. et al. Violência sexual: procedimentos indicados e seus resultados no atendimento de urgência de mulheres vítimas de estupro. Rev Bras Ginecol Obstet, v.28, n.2, p.126-35, 2006.

GOMES, R. et al. A abordagem dos maus-tratos contra a criança e o adolescente em uma unidade pública de saúde. Ciência \& Saúde Coletiva, v.7, n.2, p.275-283, 2002.

GRÜDTNER, D.I. Violência intrafamiliar contra a criança e o adolescente: reflexôes sobre o cuidado de enfermeiras. Tese (Doutorado em Enfermagem) - Curso de Pós-graduação em Enfermagem da Universidade Federal de Santa Catarina, Florianópolis, 2005. 208p.

INSTITUTO BRASILEIRO DE GEOGRAFIA E ESTATÍSTICA. Sinopse do Censo Demográfico 2010 [documento na internet]. Bahia - população residente total, urbana total e urbana na sede municipal segundo as Unidades de Federação e os municípios, 2010. Disponível em: <http://www.censo2010.ibge.gov.br/sinopse/index.php? uf=29\&dados=0>. Acesso em: 20 abr 2011.

KRUG, S.B.F. et al. O processo de trabalho na estratégia de saúde da família: o que dizem os profissionais de saúde em Santa Cruz do Sul/RS. Textos \& Contextos. Porto Alegre, v.9, n.1, p.77-88, jan-jun. 2010.

LIMA, M.A.D.S. et al. Atendimento aos usuários em situação de violência: concepções dos profissionais de unidades básicas de saúde. Rev Gaúcha de Enferm., v.30, n.4, p.625-32, dez 2009. MARTINS, C.B.G.; JORGE, M.H.P.M. Maus-tratos infantis: um resgate da história e das políticas de proteção. Acta Paul. Enferm., v.23, n.3, p.423-8, 2010.

. Negligência e abandono de crianças e adolescentes: análise dos casos notificados em município do Paraná, Brasil. Pediatria. São Paulo, v.31, n. 3, p.186-97, 2009.

MINAYO, M.C. de S. O desafio do conhecimento: pesquisa qualitativa em saúde. $9^{a}$ ed. São Paulo: Hucitec, 2006.

MINAYO, M.C. de S.; DESLANDES, S.F. (Orgs.). Análise diagnóstica da política nacional de saúde para redução de acidentes e violências. Rio de Janeiro: Fiocruz, 2007.

OLIVEIRA, C.C.; FONSECA, R.M.G.S. Práticas dos profissionais das equipes de saúde da família voltadas para as mulheres em situação de violência sexual. Rev Esc Enferm USP, v.41, n.4, p. 605-12, dez. 2007. 
PÁDUA, J.P.; VANONE, S.A.; NASCIMENTO, E. A influência da capacitação na

motivação dos Agentes Comunitários de Saúde do município de São Sebastiāo do Paraíso (MG), no ano de 2006 a 2007. Ciência e Praxis, v.2, .4, p.39-49, 2009.

PIRES, A.L.D.; MIYAZAKI, M.C.O.S. Maus-tratos contra crianças e adolescentes: revisão da literatura para os profissionais da saúde. Arq. Ciência Saúde, v.12, n.1, p.42-9, jan-mar. 2005.

RAMOS, M.L.C.O.; SILVA, A.L. Estudo sobre a violência doméstica contra a criança em unidades básicas de saúde do município de São Paulo - Brasil. Saúde Soc., São Paulo, v.20, n.1, p.136-146, jan-mar. 2011.

REICHENHEIM, M.E. et al. Violência e lesões no Brasil: efeitos, avanços alcançados e desafios futuros. The Lancet. London, p. 75-89, maio 2011.

RODRIGUES, G.S. et al. Estratégias de enfrentamento da morbidade por causas externas na atenção básica em uma região do município de Porto Alegre. Ciênc Saúde Coletiva, v.13, n.1, p.111-20, jan-fev. 2008.

SANCHEZ, R.N.; MINAYO, M.C. de S. Violência contra crianças e adolescentes: questão histórica, social e da saúde. In: LIMA, C.A. (Coord.) et al. Violência faz mal à saúde. Brasília: Ministério da Saúde, 2006. p. 29-38.

SILVA, P.A. et al. A notificação da violência intrafamiliar contra crianças e adolescentes na percepção dos profissionais de saúde. Ciênc. Cuid. Saúde, v.8, n.1, p.56-62, jan-mar. 2009.

SOUZA, E.R. de; JORGE, M.H.P. de M. Impacto da violência na infância e adolescência brasileiras: magnitude da morbimortalidade. In: LIMA, C.A. (Coord.) et al. Violência faz mal à saúde. Brasília: Ministério da Saúde, 2006. p.23-28.

VECINA, T.C.C.; MACHADO, A.L. Desafios e possibilidades para o enfrentamento da violência: fortalecendo vínculos e construindo redes. In: RIBEIRO, E.L.; TANAKA, O.Y. Atenção em saúde mental para crianças e adolescentes no SUS. São Paulo: Hucitec, 2010. p.303-17.

WOISKI, R.O.S.; ROCHA, D.L.B. Cuidado de enfermagem à criança vítima de violência sexual atendida em unidade de emergência hospitalar. Rev. Enferm. Esc Anna Nery, v.14, n.1, p.143-50, jan-mar. 2010.

\section{Notas}

${ }^{1}$ Recorte do Trabalho de Conclusão de Curso (TCC). Violência Intrafamiliar contra crianças: atuação das(os) enfermeiras(os) nas Unidades de Saúde da Família. Universidade Federal do Recôncavo da Bahia, Centro de Ciências da Saúde, 2011. Santo Antônio de Jesus, Bahia, Brasil.

${ }^{2}$ R.G. Souza e D.V. dos Santos participaram da concepção e projeto, análise e interpretação dos dados, da redação do artigo e revisão crítica relevante do conteúdo intelectual, assim como da aprovação final da versão a ser publicada. 


\section{Abstract}

Facing the children abuse at Family Health Units: the performance of nurses

Violence is considered a serious public health problem, expressed in several ways and different contexts. In this study, children abuse was highlighted, considering the vulnerability and damage to the health of these individuals. This study aimed to know the role played by nurses at Family Health Units regarding intrafamiliar violence against children in a city in the state of Bahia, Brazil. The approach is qualitative and data were collected through semi-structured interviews. The thematic content analysis was used, resulting in four central themes: "Child abuse: a problem of management?"; "Management and care (inter) acting against violence"; "What was done and what needs to be done in care" and "The 'thousand and none' difficulties". The (in)visibility of child abuse influences the performance of nurses; the unpreparedness of these professionals and their lack of understanding of violence and, consequently, of confrontation, were also identified.

> Key words: nursing; domestic violence; child's health; Family Health Program. 